\title{
Identifying teaching in wild animals
}

\author{
Alex Thornton \\ University of Cambridge, Cambridge, England \\ AND \\ Nichola J. RAIHANI \\ Institute of Zoology, Zooligical Society of London, London, England
}

\begin{abstract}
After a long period of neglect, the study of teaching in nonhuman animals is beginning to take a more prominent role in research on social learning. Unlike other forms of social learning, teaching requires knowledgeable individuals to play an active role in facilitating learning by the naive. Casting aside anthropocentric requirements for cognitive mechanisms assumed to underpin teaching in our own species, researchers are now beginning to discover evidence for teaching across a wide range of taxa. Nevertheless, unequivocal evidence for teaching remains scarce, with convincing experimental data limited to meerkats, pied babblers, and tandem-running ants. In this review, our aim is to stimulate further research in different species and contexts by providing conceptual and methodological guidelines for identifying teaching, with a focus on natural populations. We begin by highlighting the fact that teaching is a form of cooperative behavior that functions to promote learning in others and show that consideration of these key characteristics is critical in helping to identify suitable targets for future research. We then go on to discuss potential observational, experimental, and statistical techniques that may assist researchers in providing evidence that the criteria that make up the accepted operational definition of teaching have been met. Supplemental materials for this article may be downloaded from http://lb.psychonomic-journals .org/content/supplemental.
\end{abstract}

The transmission of information through animal groups by social learning is increasingly recognized as an important evolutionary force (Richerson \& Boyd, 2005; Whiten \& van Schaik, 2007). Animals from a range of taxa, including insects (Leadbeater \& Chittka, 2007), fish (Brown \& Laland, 2003), birds (Curio, 1988; Lefebvre, 2000), and mammals (Box \& Gibson, 1999; Galef \& Giraldeau, 2001), can avoid the costs associated with individual exploration by learning from others. Socially acquired information can facilitate the development of behaviors of critical fitness value, including foraging skills (Galef \& Giraldeau, 2001), predator avoidance (Griffin, 2004), communication (Janik \& Slater, 2000), and mate choice (Dugatkin, 1996; Freeberg, 2000), and may lead to the establishment of group-typical behaviors or traditions (Fragaszy \& Perry, 2003; Laland \& Hoppitt, 2003). However, in contrast to human societies, where teaching is common, it has generally been assumed that animals do not actively modify their behavior to help others to learn. Rather, social information is thought to spread as a result of naive individuals' making use of information inadvertently produced by others (Danchin, Giraldeau, Valone, \& Wagner, 2004).

The view that animals do not actively teach arose largely out of an anthropocentric perspective that treated teaching as contingent on specific cognitive abilities such as foresight, high-order intentionality, and mental state attribution (Premack \& Premack, 1996; Strauss, Ziv, \& Stein, 2002; Tomasello, Kruger, \& Ratner, 1993). Such a perspective not only restricted teaching to humans, but also, arguably, excluded many simple forms of teaching in our own species (Thornton \& Raihani, 2008; Thornton, Raihani, \& Radford, 2007). A more inclusive treatment of teaching was advocated by Ewer (1969) and later was elaborated by Caro and Hauser (1992). Rather than assuming that particular unobservable cognitive processes were prerequisites for teaching, these authors treated teaching as a functional category of behavior that serves to promote learning in others. From this perspective, teaching is seen as an active form of social learning that may depend on a variety of mechanisms.

In recent years, this functional perspective on teaching has begun to bear fruit. Studies have provided strong quantitative evidence that meerkats (Suricata suricatta; Thornton \& McAuliffe, 2006), pied babblers (Turdoides bicolor; Raihani \& Ridley, 2008), and a species of tandemrunning ant (Temnothorax albipennis; Franks \& Richardson, 2006) modify their behavior in a way that promotes learning in naive conspecifics, and there is suggestive evidence for teaching in a number of felids, as well as cetaceans, certain primates, raptorial birds, hens, and bees (for reviews, see Hoppitt et al., 2008; Thornton \& Raihani,

A. Thornton, jant2@cam.ac.uk 
2008). Far from being seen as a uniquely human capacity, teaching is now beginning to take a more prominent role in evolutionary biology, impinging on key topics including cooperation, parental care, and cultural transmission (Thornton \& Raihani, 2008). Nevertheless, the study of animal teaching is still in its infancy, and convincing examples are rare. Research on a variety of species is needed if we are to fully understand the factors favoring the evolution of teaching, its taxonomic distribution, and the relationship between the forms of teaching found in humans and in other animals. This review is intended to show how an understanding of the key characteristics of teaching may help to identify suitable target species and behaviors for future research and outlines techniques and methodologies that should aid in identifying teaching where it occurs.

\section{EXISTING EVIDENCE FOR TEACHING}

The operational definition proposed by Caro and Hauser (1992, p. 153) provided three criteria for identifying the occurrence of teaching: (1) An individual, A, modifies its behavior only in the presence of a naive observer, B; (2) A incurs some cost or derives no immediate benefit; and (3) as a result of A's behavior, B acquires knowledge or skills more rapidly or efficiently than it would otherwise. This definition both differentiates teaching from other forms of behavior that are not involved in facilitating learning in others and distinguishes teaching from other forms of social learning where knowledgeable individuals play no active role.

Although suggestive evidence for teaching under this definition exists for a number of species, only three studies have provided strong evidence consistent with all three criteria. In T. albipennis, ants that know the route to a food source modify their journeys when accompanied by a naive follower, allowing followers to investigate landmarks en route, and continue the run only when tapped by the follower's antennae. Although such tandem running causes a fourfold decrease in the leader's speed, relative to its speed when traveling alone, followers find food considerably faster when tandem running than when alone and can subsequently become leaders themselves. Moreover, followers tend to take a return route to the nest that is more direct than the leader's route on the outward journey, suggesting that the tandem run helps them learn the route (Franks \& Richardson, 2006).

Teaching has also been demonstrated in two species of free-living, cooperatively breeding vertebrates, both from the arid regions of southern Africa. Meerkats use a form of teaching to help pups learn to handle difficult prey (Thornton \& McAuliffe, 2006). Young meerkat pups are primarily given dead or disabled prey by older group members (hereafter, helpers) but are gradually introduced to live, intact prey as they grow older. Provisioning pups with live prey that might escape is costly to helpers, but pups' hunting skills improve as a result of handling practice.

In pied babblers, a group-living avian species, adults actively condition nestlings to associate a specific purr call with food by giving the call during feeding visits (Raihani \& Ridley, 2008). Upon hearing this call, nestlings begin begging, whereas fledglings approach adults that give the call. Production of the call entails energetic costs and, unlike food calling in other avian species (Leonard, Fernandez, \& Brown, 1997; Madden, Kilner, \& Davies, 2005; Maurer, Magrath, Leonard, Horn, \& Donnelly, 2003), does not appear to provide benefits to adults by increasing the efficiency of feeding visits at the nest. Instead, the benefits of conditioning young arise after fledging, since adults use the call to lead offspring away from danger and recruit them to food patches (Radford \& Ridley, 2006; Raihani \& Ridley, 2007).

Strong evidence for teaching in species of insects, mammals, and birds suggests that teaching is likely to be considerably more widespread than has been commonly assumed. However, if we are to expand our knowledge of the occurrence of teaching in nature, future studies must be directed toward potentially productive species and contexts. Although Caro and Hauser's (1992) operational definition of teaching provides the necessary criteria for identifying teaching, it does not provide a conceptual basis for understanding what teaching is and where best to look for it. As was discussed at greater length in a recent review (Thornton \& Raihani, 2008), teaching (1) is a form of cooperative behavior, (2) functions to facilitate learning in others, and (3) involves the coordinated interaction of a donor and a receiver of information. The first two of these characteristics, in particular, can be used to make predictions as to where teaching may be found in nature, whereas the third characteristic may help researchers to predict the form that teaching will take.

Below, we begin by outlining how consideration of the key characteristics of teaching may assist in identifying likely species and contexts in which teaching may be found. We then discuss observational, experimental, and statistical techniques of use in determining whether given patterns of behavior fulfill Caro and Hauser's (1992) three criteria (summarized in Table 1).

\section{WHERE TO LOOK FOR TEACHING}

\section{Teaching As Cooperation}

Teaching is a form of cooperation in that a teacher's behavior benefits others but has no immediate benefit for the teacher (Thornton \& Raihani, 2008). As with any other cooperative behavior, teaching will be favored by selection only if the long-term fitness benefits of investing in teaching outweigh the short-term costs. Future studies should therefore focus on species and contexts in which this condition is likely to be met.

Inclusive fitness theory suggests that teaching may be particularly common among closely related individuals, such as colony members in eusocial insect societies or parents and their own offspring (Hamilton, 1964; West, Griffin, \& Gardner, 2007). Consequently, teaching may be especially common as a form of parental care promoting offspring development.

In certain contexts, teachers may also derive substantial direct fitness benefits. For example, in meerkats and 
Table 1

Guidelines to Identifying Teaching

\begin{tabular}{|c|c|}
\hline $\begin{array}{l}\text { 1. Identify Likely Candidate Species and Cont } \\
\text { Consider the Key Characteristics of Teaching: }\end{array}$ & \\
\hline $\begin{array}{l}\text { Teaching is a form of cooperation } \\
\text { Teachers must obtain direct/indirect fitness } \\
\text { benefits through their actions } \\
\text { Contributions to teaching predicted to vary } \\
\text { with costs and benefits incurred }\end{array}$ & $\begin{array}{l}\text { Likely species/contexts: } \\
\text { Parental care } \\
\text { Cooperative breeders }\end{array}$ \\
\hline $\begin{array}{l}\text { Teaching promotes learning } \\
\text { Consider: Is teaching necessary? }\end{array}$ & $\begin{array}{l}\text { Necessary criteria: } \\
\text { High costs/few opportunities for individual learning or inadvertent social learning } \\
\text { Information/skill acquisition provides major fitness benefits }\end{array}$ \\
\hline $\begin{array}{l}\text { 2. Examine the Evidence for Teaching } \\
\text { Consider Caro \& Hauser's (1992) Three Criteria }\end{array}$ & \\
\hline Modification of behavior in the presence of naiv & ndividuals \\
\hline $\begin{array}{l}\text { Identify patterns of behavior that stand out } \\
\text { from the species' normal repertoire }\end{array}$ & $\begin{array}{l}\text { Requires good understanding of the species' ecology and natural history } \\
\text { Habituation may be a useful tool }\end{array}$ \\
\hline $\begin{array}{l}\text { Consider the nature of the knowledge } \\
\text { transmitted }\end{array}$ & Necessary data: \\
\hline $\begin{array}{l}\text { Declarative knowledge (knowing that): Fixed } \\
\text { teaching }\end{array}$ & Behavior of knowledgeable individuals in presence and absence of naive conspecifics \\
\hline $\begin{array}{l}\text { Procedural knowledge (knowing how): Pro- } \\
\text { gressive teaching }\end{array}$ & $\begin{array}{l}\text { Behavior of knowledgeable individuals in presence and absence of naive conspecifics } \\
\text { Longitudinal data charting progression of teaching over time }\end{array}$ \\
\hline Costs (or lack of immediate benefits) to teachers & \\
\hline Generate alternative hypotheses & $\begin{array}{l}\text { Generate predictions of what is expected if observed behavior is or is not a form of teach- } \\
\text { ing. Might putative teachers gain benefits from their actions that are unrelated to facilitating } \\
\text { learning in others? }\end{array}$ \\
\hline Consider the types of cost involved & Quantifying magnitude: \\
\hline $\begin{array}{l}\text { - Time costs } \\
\text { - Lost investments }\end{array}$ & $\begin{array}{l}\text { Data on time taken to perform modified "teaching" behavior versus unmodified behavior } \\
\text { Teaching of hunting skills: quantitative longitudinal data on live prey lost by young } \\
\text { Comparisons of adult hunting success when alone or accompanied by young }\end{array}$ \\
\hline - Danger & $\begin{array}{l}\text { Qualitative or (if possible) quantitative assessments of potential danger (e.g., meerkat pups } \\
\text { being stung by live scorpions; babbler nestling predation as a result of purr calling attractin } \\
\text { predators) }\end{array}$ \\
\hline & $\begin{array}{l}\text { Teaching about novel foods: evidence that adults willingly sample unknown foods before } \\
\text { donating to young }\end{array}$ \\
\hline - Energetic costs & $\begin{array}{l}\text { Belly size in large carnivores in relation to investment in teaching (donating live prey to } \\
\text { young) }\end{array}$ \\
\hline & Weight data \\
\hline & $\begin{array}{l}\text { Individual contributions to teaching (contributions predicted to be low for individuals that } \\
\text { are in poor condition or investing heavily in growth) }\end{array}$ \\
\hline Learning by pupils as a result of teacher behavio & \\
\hline Evidence of improvement in pupil abilities & Longitudinal data on pupil behavior \\
\hline $\begin{array}{l}\text { Exclude confounding variables (e.g., growth/ } \\
\text { maturation) }\end{array}$ & Useful techniques: \\
\hline - Experimental methods & $\begin{array}{l}\text { Prevent exposure to teaching } \\
\text { Be a teacher: increase exposure to learning opportunities (e.g., release live prey; simulate } \\
\text { prey release with lures; playbacks simulating teacher behavior) }\end{array}$ \\
\hline - Statistical techniques & $\begin{array}{l}\text { Begin exposure to teaching earlier in life (e.g., playback experiments to young pupils) } \\
\text { Correlations between teacher behavior and rates of pupil knowledge/skill acquisition } \\
\text { Multifactorial analyses to control for the effects of confounding variables }\end{array}$ \\
\hline
\end{tabular}

pied babblers, helpers assist parents in teaching young. Such helpers may gain indirect benefits from assisting related young but may also benefit directly-for example, by increasing the size of the group to which they belong (Kokko, Johnstone, \& Clutton-Brock, 2001; Thornton \& Raihani, 2008) and reducing the burden of caring for young by accelerating their development. The net fitness benefits from teaching in cooperative breeders may also be magnified because the costs of teaching are divided among group members (Thornton, 2008b), possibly accounting for the fact that, to date, the strongest evidence for teaching has been found in cooperatively breeding species.
In common with other cooperative activities, individual contributions to teaching should vary in response to the costs and benefits incurred (Thornton, 2008b), raising two important issues for future research. First, the balance of costs and benefits may be highly sensitive to environmental conditions. Second, analysis of individual contributions may allow us to determine whether or not a particular behavior should be considered a form of teaching. We discuss these two issues below.

The first issue is that teaching is likely to be manifested to differing degrees under varying conditions. For instance, for meerkats, the cost of provisioning live prey to pups varies according to the characteristics of the prey. 


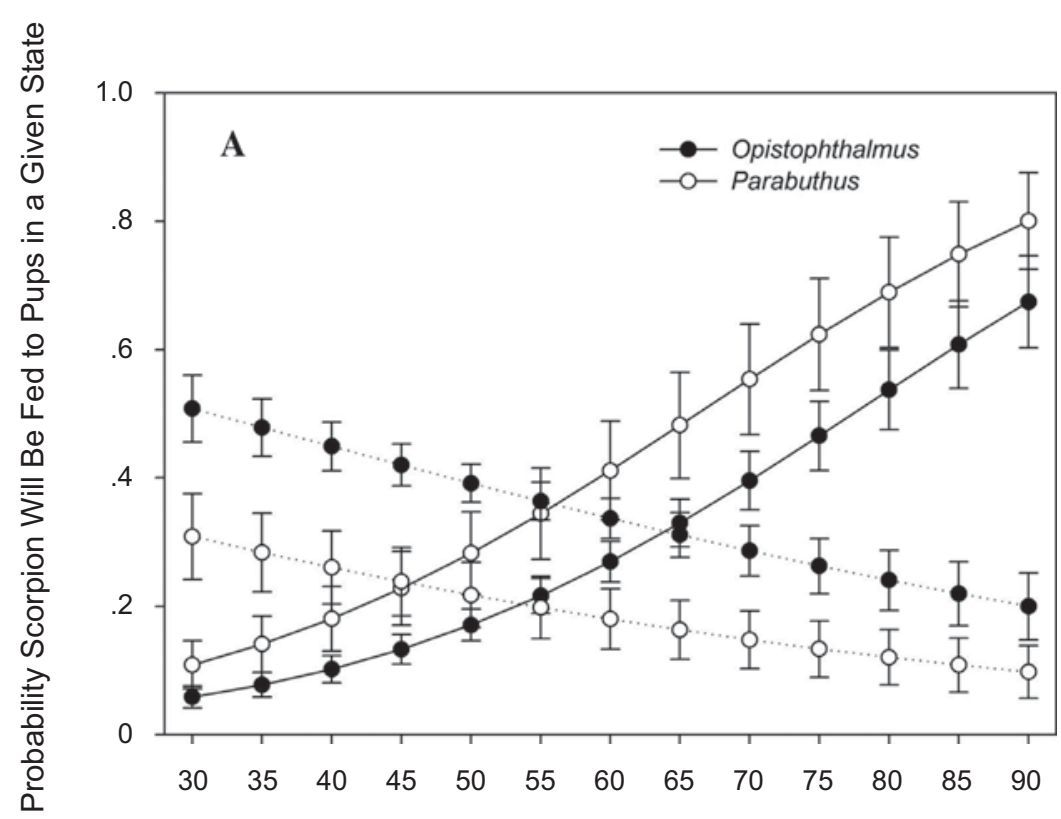

Pup Age

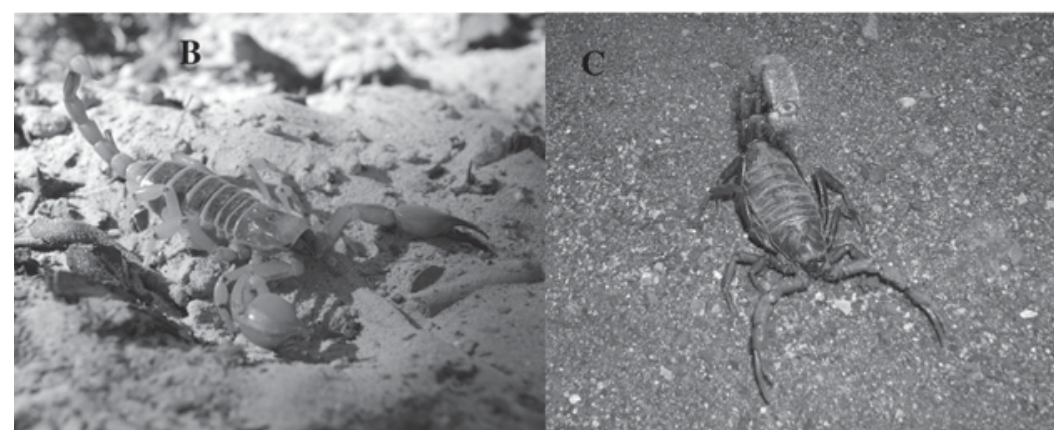

Figure 1. (A) Effects of pup age on the proportion of scorpions of the genera Opistophthalmus and Parabuthus that adult meerkat helpers provisioned either dead (dotted lines) or intact (solid lines) to pups (lines represent means $\pm S E$ s from generalized linear mixed model [GLMM] analyses). As pups grow older, scorpions are less likely to be killed prior to provisioning (GLMM: $\chi^{2}=7.56, p=.006$; see Table S1 in the supplement) and more likely to be given intact to pups (GLMM: $\chi^{2}=24.49, p<.001$ ). Aggressive, large-pincered Opistophthalmus scorpions (B) are more likely to be killed prior to provisioning (GLMM: $\chi^{2}=9.22, p=.002$ ) and less likely to be given away intact $\left(\chi^{2}=5.81, p=.016\right)$ than the more venomous but less aggressive Parabuthus scorpions (C). Photo credits: Tom Flower.

The loss of a large prey item represents a greater cost than does loss of a small item, so adults are more likely to kill a large than a small prey before feeding it to pups (Thornton \& McAuliffe, 2006). Similarly, adults spend more time monitoring pups' handling attempts if the prey is large and alive than if it is small and dead (Thornton, 2008b).

Adult meerkats even show distinct variation in their treatment of scorpions of different genera. We used generalized linear mixed models (GLMMs) to determine whether meerkats' tendency to feed pups dead, disabled (live but stingless), or intact scorpions differed depending on whether the scorpion was of the genus Parabuthus or Opistophthalmus. Although there was no significant difference in the probability that scorpions of either genus would have their stings removed before being given to pups, Parabuthus scorpions were less likely to be killed and more likely to be provisioned intact than Opistophthalmus scorpions (Figure 1; see also Table $\mathrm{S} 1$ in the supplemental materials). This result may appear paradoxical, given that Parabuthus scorpions are considerably more toxic than Opistophthalmus scorpions (Leeming, 2003), but may be explained by the fact that Opistophthalmus scorpions are more aggressive and often succeed in inflicting painful pinches on inexperienced meerkats (A.T., personal observation).

Pied babblers also adjust their investment in teaching in response to current costs and benefits. We measured individual contributions to teaching by calculating the proportion of nestling feeds that were accompanied by a purr call on the day of fledging (when most purr calls are given; 


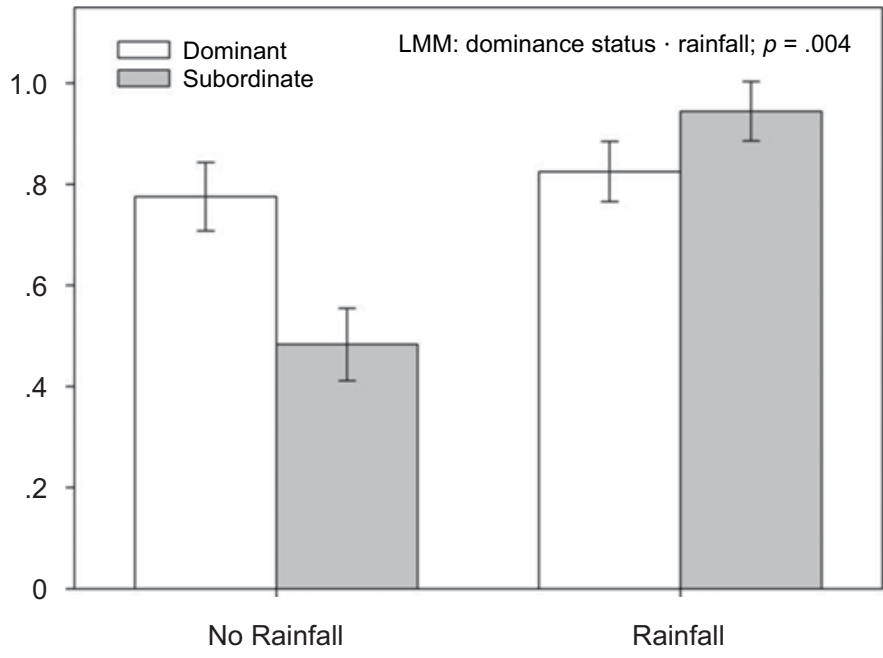

Rainfall in Previous 30 Days

\begin{abstract}
Figure 2. Effects of rainfall on contributions to teaching by dominant and subordinate pied babblers. Contributions by dominants are unaffected by rainfall, but subordinates produce purr calls on a significantly lower proportion of nest feeds during periods of no rainfall (LMM: dominance status * rainfall; $\chi^{2}=8.06, p=.004$; see Table $S 2$ in the supplement). Bars show means $\pm S E$ s.
\end{abstract}

Raihani \& Ridley, 2007) and used a linear mixed model to examine how contributions varied in relation to environmental conditions and individual characteristics (Table S2 in the supplement). Subordinate individuals' contributions to teaching declined in periods of low rainfall, but no such effect was evident among dominants (Figure 2). The greater sensitivity of subordinates than of dominants to environmental conditions may reflect the fact that subordinates are typically younger than dominant breeding individuals (Raihani, 2008) and have poorer foraging skills (Ridley \& Raihani, 2007). Consequently, subordinates may be less able or motivated to invest in costly teaching behaviors when food availability is low. Furthermore, subordinate babblers face a trade-off between investing in the offspring of dominant breeders and the need to conserve resources for their own future reproduction and may, therefore, benefit from helping less when the costs of helping are elevated. In common with previous results (Raihani \& Ridley, 2008), we also found a significant effect of sex, with males purr calling in a higher proportion of feeds than did females. This suggests that males, who tend to remain on the natal territory for longer, may experience a greater net benefit than do females from investment in teaching. Similar sex biases in helping behavior have been reported in several other species (e.g., Caffrey, 1992; Clutton-Brock et al., 2002; Woolfenden \& Fitzpatrick, 1984), particularly where philopatric helpers accrue direct benefits from increasing the survival of young (e.g., through group augmentation; Kokko et al., 2001).

Together, the results above demonstrate an acute sensitivity to the benefits of teaching in meerkats and pied babblers and highlight the need to take subtle environmental parameters and individual characteristics into account when attempting to identify teaching. Such sensitivity to environmental conditions suggests that, whenever possible, the search for evidence of teaching needs to be undertaken under natural conditions.

The second issue is that individuals that incur the greatest costs of teaching are expected to show lower investment in teaching, and patterns of behavior that violate this relationship are, consequently, unlikely to be a form of teaching. For instance, meerkats teach pups by providing them with otherwise unavailable opportunities to handle live prey. Giving away live prey is considerably more costly than feeding pups dead prey items, because of the need to monitor pups' handling attempts and the risk that the prey will escape or injure the pup (Thornton $\&$ McAuliffe, 2006). Consequently, young helpers that are still investing in their own growth typically contribute less than older helpers to the teaching of pups: When they feed pups, they are less likely than older helpers to give away live prey, and they tend to spend less time than do older helpers watching pups handling prey (Thornton, 2008b). A similar tendency for young helpers to contribute relatively little to cooperative activities is common in many social species (Clutton-Brock, Brotherton, et al., 2001; Clutton-Brock et al., 2000; Heinsohn \& Legge, 1999).

The pattern of reduced contributions by young meerkat helpers to the provisioning of live prey and monitoring of pups' handling attempts is in contrast to that observed for direct feeding. Direct feeding occurs when, rather than dropping a prey item on the floor in front of a pup, a helper allows a pup to take food directly from its mouth. Ewer (1963) suggested that direct feeding may be a form of teaching whereby adults entice pups to sample novel foods and, thereby, promote the incorporation of these 
foods into the pups' diet. However, direct feeding is used disproportionately by young helpers that cannot afford the costs of investing heavily in teaching, and there is no clear evidence that it is used primarily for novel prey types. This suggests that, rather than being a costly contribution to pups' education, direct feeding is a strategy employed by helpers to reduce the costs of feeding pups by facilitating food transfer (Thornton, 2008a). Similar analyses of the contributions of individuals that incur different costs may help to determine whether behaviors of other species are likely to be forms of teaching.

\section{Teaching Promotes Learning}

Teaching serves to promote learning in others. Behavior that is known to have an alternative primary function cannot, therefore, be considered a form of teaching (Thornton $\&$ Raihani, 2008). For example, as required by the first two of Caro and Hauser's (1992) criteria, animals that provision their offspring invariably modify their behavior in the presence of naive individuals and incur some immediate cost. Moreover, provisioned young may inadvertently learn to prefer the food with which they are provisioned, thereby fulfilling Caro and Hauser's third criterion for teaching (Hoppitt et al., 2008). However, since the primary function of provisioning is nutritional and any learning that occurs is an inadvertent by-product of providing nutrition, it is unproductive to consider provisioning a form of teaching. Only in cases where provisioning behavior itself is modified to facilitate learning, as is the case in meerkats (Thornton \& McAuliffe, 2006), can teaching be said to occur.

Given that teaching serves to promote learning in others, it should be expected only in contexts in which opportunities for individual learning or inadvertent social learning are either lacking or entail high costs (Thornton $\&$ Raihani, 2008). For example, since the development of motor skills needed for hunting in carnivores typically requires practice, simply observing others is unlikely to facilitate learning. Moreover, since young animals seldom find prey themselves, opportunities to practice the motor skills needed to subdue prey are lacking, and incompetent handling attempts may be dangerous. However, teaching is not to be expected in all carnivorous animals. For example, we expect teaching to be considerably more common in solitary hunters, such as mongooses, felids, killer whales, and raptorial birds, than in group-hunting species, such as canids, where young can gain considerable experience from joining more experienced individuals on the hunt. Similarly, teaching of foraging skills is unlikely to occur in species in which skills or information are easily learned through observation. The great apes, whose offspring spend extended periods foraging alongside adults and can learn foraging and tool-using skills by observing their elders (Lonsdorf, 2006; Matsuzawa et al., 2001), are therefore unlikely candidates for teaching, at least in those contexts. Researchers considering whether to invest time and effort in searching for evidence for teaching in a particular species or context are therefore advised to ask the question: Is teaching necessary? If naive individuals can acquire knowledge or skills relatively easily without assistance, research efforts would best be targeted elsewhere.

\section{ASSESSING EVIDENCE FOR CARO AND HAUSER'S CRITERIA}

Once a promising candidate species and context have been identified, the next step is to assess the evidence for the three criteria outlined by Caro and Hauser (1992). Although there has been debate over what precisely constitutes teaching (Csibra, 2007; Leadbeater, Raine, \& Chittka, 2006; Thornton et al., 2007), Caro and Hauser's definition is now widely accepted as a rigorous, conservative means of establishing its occurrence. Here, we outline methods and techniques for establishing whether the three criteria have been met. Since two out of the three existing studies that provide strong evidence for teaching in Caro and Hauser's sense of the term were conducted in the wild and natural conditions may be difficult to replicate in captivity, we focus on examining teaching in free-living animals.

\section{Criterion 1: Modification of Behavior \\ in the Presence of Naive Individuals}

Caro and Hauser's (1992) first criterion distinguishes teaching from inadvertent forms of social learning in which naive individuals learn from conspecifics going about their usual behavior. If a species' ecology and behavior under natural conditions are well understood, this is the easiest of the three criteria to assess, since modifications of the usual behavioral repertoire will be salient to experienced observers. Indeed, both of our studies of meerkats and babblers were inspired by observations of two unusual behaviors: (1) adult meerkats bringing live prey to pups that then often lose the prey delivered to them and (2) babblers purr calling and wing fluttering at the nest.

Fixed teaching. The data needed to assess Caro and Hauser's (1992) first criterion will vary according to the nature of the knowledge transmitted. Animals engaging in fixed teaching perform a single type of action to promote learning of declarative knowledge of contents and facts (knowing that; Thornton \& Raihani, 2008). Teaching of routes by T. albipennis (Franks \& Richardson, 2006) and the meaning of purr calls by pied babblers (Raihani \& Ridley, 2008) are established examples of fixed teaching. Other putative examples of fixed teaching include parental behavior by hens (Gallus gallus domesticus; Nicol \& Pope, 1996) and callitrichid primates (Rapaport \& Brown, 2008), which may teach offspring that certain food items are unsafe (hens) or safe (callitrichids). In what is perhaps the most convincing evidence of teaching of food choice to date, a recent study by Clarke (2010) showed that whitetailed ptarmigan hens (Lagopus leucurus) performed distinctive feeding displays toward high-protein plants when in the presence of chicks. These displays served to attract chicks to the plants, and the subsequent long-term prevalence of different plant species in the chicks' diet was positively correlated with the frequency of maternal feeding displays associated with that plant.

In the context of fixed teaching, data comparing the behavior of knowledgeable individuals in the presence and absence of naive conspecifics will suffice to establish whether Caro and Hauser's (1992) first criterion has been met. However, it is important to consider possible 
confounding factors. For example, when teaching in the context of parental care is considered, comparison of parents with offspring with younger animals without offspring must be avoided, since any differences in behavior of parents and nonreproductive individuals might be age related and not caused by the presence of offspring. Ideally, researchers should aim to collect data on the same individuals when offspring are or are not present. Failing this, comparisons should use individuals of the same age that do or do not have offspring. Multifactorial statistics (controlling for repeated measures of individuals, if necessary) may be an important tool in assessing the impact of different factors and teasing apart the degree to which behavioral differences are due to the presence of naive individuals.

Progressive teaching. In progressive teaching of procedural knowledge (knowing how) to promote the development of skills such as hunting, teachers modify their teaching behavior in accordance with pupils' stage of skill development (Thornton \& Raihani, 2008). Consequently, studies of progressive teaching require data not only on differences in behavior when naive individuals are or are not present, but also on the progression of teaching behavior over time. Longitudinal observations on the same individuals may be particularly useful in generating data adequate to establish that progressive teaching has occurred. To allow rigorous analyses of temporal patterns while controlling for potential confounding factors, research on progressive teaching is likely to require extensive periods of data collection. The observational data used in analyses of teaching in meerkats, for example, was collected over more than 2,000 $\mathrm{h}$ of observation over a 22 -month period (Thornton \& McAuliffe, 2006).

Although the first of Caro and Hauser's (1992) three criteria is the easiest to assess, it may often be difficult to collect sufficiently detailed data in the wild if study animals are nervous in the presence of humans and must be observed from a distance. In the studies of meerkats and babblers, this issue was overcome by using populations that were habituated to close observation.

Habituation can require a great deal of initial effort and may take a considerable length of time to reap rewards. It is, however, an extremely effective tool in the study of wild animals (Williamson \& Feistner, 2003) and has been used successfully on a range of birds, small carnivores, and primates (Table S3 in the supplement; some large mammalian carnivores, although not observable on foot for safety reasons, have also been habituated to the presence of vehicles-e.g., cheetahs [Acinonyx jubatus; Caro, 1994], lions [Panthera leo; Stander, 1992], African wild dogs [Lycaon pictus; Creel \& Creel, 2002], and spotted hyenas [Crocuta crocuta; Hofer \& East, 2008]). It may be argued that habituation changes animals' natural behavior, but changes in behavior resulting from habituation are likely to be considerably less severe than those caused by caging animals in artificial environments in the absence of predators, with abundant food and little stimulation. The ultimate goal of habituation should be to reach a stage where study animals pay no more attention to human observers than they do to other large, nonthreatening animals in their environment. Habituated meerkats and pied bab- blers, for example, do not show fear, look up, or move away when trained human observers are among them (A.T. and N.J.R., personal observation; Clutton-Brock, 2007), and in a habituated population of the Arabian babbler (Turdoides squamiceps), Wright (1997) showed that close observer proximity had no significant effect on any of 17 different behavioral variables. Habituation therefore allows collection of extremely detailed data under ecologically valid conditions. It may also greatly facilitate field experiments involving individuals of particular interest. For example, it has proven difficult to determine whether adult callitrichid primates in the wild teach offspring about novel food by preferentially provisioning them with rare food items or whether patterns of provisioning reflect nutritional requirements of the young (Rapaport, 2006; Rapaport \& Brown, 2008). The question of the influence of food novelty on provisioning of young could be resolved by presenting different novel and familiar foods of equivalent nutritional value. If adults usually eat novel food items when alone but preferentially donate them to offspring when offspring are present, this would provide strong evidence for the first of Caro and Hauser's (1992) criteria.

Mechanisms underpinning modification of behavior and teacher sensitivity. Although evolutionary approaches to the study of teaching focus on function, it is also important to address mechanistic questions. Progressive teaching requires the existence of mechanisms allowing teachers to tailor their behavior to the skill level of their pupils. The precise mechanisms employed to achieve this goal are likely to vary across contexts. For example, in very stable environments, relatively stereotyped modifications to behavior associated with hormonal changes following parturition may be sufficient to ensure a match between teaching behavior and the skill level of pupils (Caro \& Hauser, 1992). Evidence for hormonal control of teachers' behavior could be assessed by correlating hormonal levels in blood or fecal samples with temporal changes in behavior. In other cases, teachers may be responsive to behavioral cues indicating pupils' age or skill level. Researchers may therefore investigate the mechanisms of teaching by manipulating the cues available. For example, meerkat helpers often find prey when they are out of sight of pups, modify the prey at the site of capture, and then carry it to a begging pup. Observation of such sequences of behavior led to the hypothesis that helpers modify their behavior in response to age-related changes in pups' begging calls. Playback experiments confirmed the hypothesis; when calls of old pups were played to groups with young pups, helpers began to bring live prey, even though the pups were too young to handle live prey. Conversely, playing back the calls of young pups to groups with old pups caused helpers to bring dead prey to the young (Thornton \& McAuliffe, 2006).

Like progressive teaching, fixed teaching must also be supported by mechanisms allowing each party in a teaching interaction to respond appropriately to cues from the other (Thornton \& Raihani, 2008). Hoppitt et al. (2008) suggested that all forms of teaching are likely to have evolved by building on preexisting mechanisms for inadvertent social learning. Teaching in T. albipennis, for 
example, is likely to employ an active form of local enhancement, where the action of a leader attracts followers to a specific location. Evidence that a species is capable of the relevant form of inadvertent social learning may therefore support claims for an equivalent form of active social learning (i.e., teaching). Moreover, teachers may have evolved mechanisms allowing sensitivity to current circumstances. Richardson, Houston, and Franks (2007), for example, showed that T. albipennis leaders' investment in a bout of teaching (a tandem run to or from a nest site) is responsive to the time already invested in that bout, the quality of the goal (poor or good quality nests), and the speed of the follower. Richardson et al.'s techniques of interrupting bouts of teaching and altering the quality of goals may be of great use in assessing the degree of sensitivity shown by teachers in other species as well. Further manipulations, such as experimentally reducing pupils' ability to learn (e.g., Richardson et al., 2007), may also prove helpful in analyzing teaching in vertebrate species but should be given careful ethical consideration.

Flexible teaching? All evidence to date suggests that, in contrast to teaching in humans, which is often flexible and used in multiple contexts, teaching in other species is an adaptation in response to a specific problem and is not involved in the transmission of novel skills and innovations (Premack, 2007; Thornton \& Raihani, 2008). However, the possibility remains that some species may show more humanlike flexibility and employ teaching to help naive individuals learn in multiple different situations. Such a capacity could be detected using demonstrator-observer techniques, as commonly employed in social-learning experiments. For instance, if adult demonstrators trained to obtain food from an experimental apparatus recognize the ignorance of youngsters (through either behavioral cues or a capacity for knowledge attribution), the adult demonstrators might change their behavior in such a way as to make it easier for young observers to learn to operate the apparatus. In meerkats, quite the opposite occurs; demonstrators in diffusion experiments are more likely to block the approach of young than of old observers (Thornton \& Malapert, 2009). Indeed, despite the great proliferation of social-learning experiments in recent years (see Whiten \& Mesoudi, 2008, for a review), we are aware of only one experiment in which there was any suggestion of teaching. In this experiment, wild Florida scrub jays, Aphelocoma coerulescens, were trained to dig for food in the center of a plastic ring. The jays generally ate the food and carried on digging or moved away. However, on three occasions, an adult in the presence of a juvenile uncovered a food item and then pointed at the food with its beak until the juvenile took the food (Midford, Hailman, \& Woolfenden, 2000). Other, similar experiments may help to determine whether adults consistently change their behavior when youngsters are present in different contexts and whether adult behavior does facilitate learning by the young.

\section{Criterion 2: Quantifying Costs to Teachers}

Generating alternative hypotheses. Caro and Hauser's (1992) second criterion excludes instances in which putative teachers obtain immediate rewards from their actions that are not contingent on facilitating learning in others. A useful tool for determining whether putative teachers are acquiring immediate rewards is to generate alternative hypotheses with realistic predictions of what would be expected if a given behavior is or is not a form of teaching. For example, carnivores that donate live prey to their offspring may be (1) optimizing the efficiency of food transfers by saving themselves the effort of killing the prey or (2) teaching young by providing them with opportunities to practice prey handling (Thornton \& Raihani, 2008). Under Hypothesis 1, adults would be expected to donate live prey only to older offspring that are likely to catch and kill it. The finding that meerkats, other mammalian carnivores, and raptorial birds give away live prey to young offspring that regularly lose the prey they are given would provide support for Hypothesis 2.

In pied babblers and other birds, the production of food calls during feeding visits at the nest could serve to teach young to associate the calls with food but, alternatively, could produce immediate benefits. Raihani and Ridley (2008) suggested two alternative hypotheses to teaching in such circumstances. First, food calls may indicate impending food delivery to chicks and cause them to beg, thus improving the efficiency of food transfers. If this were the case, calls should precede food delivery and should be most common when chicks are young, since younger nestlings are typically less responsive than older nestlings to the sight of adults (Clemmons, 1995; Leonard et al., 1997; Lessells, Rowe, \& McGregor, 1995; Maurer et al., 2003). Instead, in pied babblers, purr calls accompany, rather than precede, food transfers. Furthermore, adults begin giving purr calls during feeding visits a week before nestlings begin to respond to food calls by begging (Raihani \& Ridley, 2007, 2008), suggesting that purr calling does not function to increase provisioning efficiency. Second, food calling, of which purr calls are an example, may serve to signal contributions to cooperative rearing, allowing provisioners to reap direct benefits, such as increasing social prestige (Zahavi, 1995) or signaling payment of rent to dominant individuals for residing on their territory ( pay-to-stay hypothesis; Gaston, 1978). Under such signaling hypotheses, rates of purr calling would be expected to remain constant throughout the nestling period. However, in pied babblers, the rate of calling increases with nestling age, mitigating against the hypothesis that provisioners use food calls to advertise feeding visits (Raihani \& Ridley, 2008).

Identifying costs. The potential costs of teaching may be divided into four principal but potentially overlapping categories: (1) time that could have been spent performing other activities, (2) lost investments, (3) placing the teacher or the pupil in danger, and (4) energetic costs. We address each of these potential costs in turn, suggesting methods that may be used to assess them.

Time costs. Assessments of time costs must compare the time taken to perform the modified behavior involved in teaching with the time taken to perform unmodified behavior. For example, a single bite taking a fraction of a second is sufficient for an adult meerkat to kill a captured prey item. Giving a pup a live prey item is costly, relative to provisioning dead prey, because donation of live prey 
requires additional time spent monitoring pups, assisting their handling efforts, and retrieving prey that the pups lose (Thornton \& McAuliffe, 2006). Similarly, a recent study proposed that Atlantic spotted dolphin (Stenella frontalis) mothers use salient movements during hunting to draw calves' attention to prey and teach them hunting techniques (Bender, Herzing, \& Bjorklund, 2009). It is unclear whether these movements do serve to teach the young, but hunting in this way clearly takes longer than the standard hunting method of unaccompanied dolphins.

Lost investments. Animals that provision young with live prey incur substantial costs of lost investment if the young lose the prey. Studies of teaching in carnivores can quantify the costs of lost investments by recording longitudinal data on the proportion of live prey lost by the young as they mature. Such data not only allow investigation of changes in the costs of teaching, but also provide records of improvements in offspring prey-handling abilities. Of course, the magnitude of costs will vary with the relative size of the predator and prey. Meerkats may eat hundreds of small prey items each day, so a single lost scorpion represents a relatively low cost. In contrast, if a cheetah cub loses a gazelle, the family may not eat again for several days (Caro, 1994).

Certain species have also been suggested to teach by allowing offspring to accompany them on hunts and, thus, providing the young with opportunities to practice their hunting skills (lions [Panthera leo; Schenkel, 1966], killer whales [Orcinus orca; Hoelzel, 1991]), although the evidence is inconclusive. The presence of the young on hunts may cause costs of lost investment in a hunting bout if the young reduce the probability of success. Comparisons of hunting success by the same individuals in the presence or absence of the young would permit assessment of such costs.

Danger. Certain forms of teaching may place either teachers or pupils in dangerous situations, particularly when teaching is involved in promoting behavioral development in young animals that, because of their small size and poorly developed skills, are often especially vulnerable. Due to the low probability of observing dangerous situations directly, assessments of the dangers of teaching will generally be qualitative, rather than quantitative. For example, although it stands to reason that young carnivores risk injury as a result of incompetent attempts at handling live prey, quantitative data are lacking. Similarly, purr calling in pied babblers may attract the attention of predators, but since predation events are rarely observed, the risks of predation incurred by purr calling are difficult to assess (Raihani \& Ridley, 2008). Nevertheless, a small number of studies have provided direct evidence for dangers incurred through putative teaching activities.

In killer whales, it has been suggested that adults teach the young to catch pinnipeds on breeding beaches by intentionally stranding themselves, and the young have been found stuck on land and facing death (Guinet \& Bouvier, 1995). It has been suggested that macaque (Macaca spp.) mothers teach infants to locomote independently by breaking contact and using retrieval signals to lure them back (Maestripieri, 1995, 1996). It is still unclear whether such behaviors by adult macaques promote learning in the young, but the dangers are clear, since infants out of contact with their mothers risk being kidnapped by other group members and kidnapping has been known to lead to death through dehydration or starvation (Maestripieri, 1995).

In species in which adults are thought to teach the young about novel foods, one might expect adults to be prepared to incur the risks of ingesting toxins in order to ascertain that unknown foods are safe to eat before then transferring the foods to the young. However, evidence for such behavior is lacking. For example, golden lion tamarins (Leontopithecus rosalia) are equally likely to provision offspring with food that neither they nor the young have previously encountered as with food that parents are familiar with but is novel for the young (Rapaport, 1999). Future claims of teaching in this context would be considerably strengthened by evidence that adults are willing to incur the risks of sampling unknown foods in order to acquire information that can then be passed on to the young. The only experimental test of a willingness by adults to sample food to protect their young showed that Norway rat (Rattus norvegicus) mothers do not make sacrifices of this kind to teach their offspring (Galef, Whiskin, \& Dewar, 2005).

Energetic costs. Teaching will often involve energetic costs, through the metabolic requirements of modifying behavior, lost foraging time, or the loss of prey and attempts to recapture it. Energetic costs are often difficult to quantify directly, particularly in wild animals. Nevertheless, a number of studies have shown that it is possible. In cheetahs, for example, Caro (1994) used mothers' belly size as a measure of their hunger, since larger bellies indicate a recent meal. He found that hungrier mothers were less likely to release live prey, thus providing evidence for the existence of energetic costs of prey release. Of course, measures of belly size may reflect natural size variation or parasite load, as well as hunger. Still, in large carnivores, where differences in belly size are easily observable, belly size can provide a crude, but useful, index of hunger.

In smaller species, it may often be possible to obtain more direct measures of energetic costs by weighing individuals. In the wild, weighing will be easiest in habituated populations where individuals can be trained to step onto scales in return for small food rewards (see Table S3 in the supplement). Techniques have also been developed to remotely record weights when individuals step onto scales (e.g., pied flycatchers [Ficedula hypoleuca; Wright, Hinde, Fazey, \& Both, 2002] and carrion crows [Corvus corone; Canestrari, Marcos, \& Baglione, 2007]). Measurements of weight change can provide direct quantitative evidence of the costs of investment in teaching. For example, high rates of purr calling by pied babblers are associated with reduced weight gain, indicating that there is a substantial energetic cost of engaging in the behavior (Raihani \& Ridley, 2008). In contrast, in meerkats, although there are clear time and lost investment costs associated with provisioning live prey, these do not translate into detectable effects on either body weight or daily weight gain. The absence of a relationship between weight and contributions to teaching suggests that the costs of teaching in meerkats 
are relatively low and are, therefore, particularly likely to be outweighed by the delayed benefits of promoting learning in others (Thornton, 2008b).

Individual contributions to teaching will vary with the costs incurred (Thornton, 2008b), and body weight data may be useful in directly assessing cost, since individuals in poor condition will be expected to contribute relatively little to teaching. Data showing the opposite effect would cast doubt on any claims of teaching. Energetic costs may also be manipulated directly. For example, reductions in hunger through experimental provisioning would be expected to result in increased contributions to teaching. Similarly, in species with multiple offspring, temporary offspring removal experiments would reduce the burden on putative teachers and, therefore, would be expected to result in increases in teaching behavior directed at the remaining offspring (see Clutton-Brock, Russell, et al., 2001 , for positive effects of temporary pup removals on contributions to cooperative care in meerkats). The prediction of increased teaching when the energetic burden on potential teachers has been reduced has received some support from observational data on meerkats, where helpers spend more time monitoring pups handling prey if the pups are in small litters (Thornton, 2008b).

\section{Criterion 3: Do Naive Individuals Learn?}

The purpose of teaching is to help others to learn. No claim of teaching can therefore be complete without compelling evidence that naive individuals learn something and that learning occurs as a result of the actions of putative teachers. However, such evidence is often difficult to obtain. Indeed, of the 60 studies reviewed by Thornton and Raihani (2008), only 4 provided strong evidence for Caro and Hauser's (1992) third criterion.

The difficulty in producing unequivocal support for Caro and Hauser's (1992) third criterion is due to two factors. First, detecting improvements in the skills or knowledge of naive individuals often requires longitudinal data collected over long time periods. Caro's (1994) studies of wild cheetahs, for instance, detected relatively little improvement in cubs' hunting abilities over 10 months following their first introduction to live prey. Second, any improvements that are detected may be caused by factors such as increased size or dexterity through growth, maturation, and individual experience, rather than by the actions of putative teachers. Such confounding factors must be ruled out to determine whether teaching has occurred. Maestripieri's $(1995,1996)$ studies of parental encouragement in macaques, for example, showed that the infants of mothers that gestured and broke contact at high rates acquired motor skills more rapidly but were unable to ascertain whether the link between mothers' behavior and motor skill acquisition by the young was causal. The challenge for researchers is to implement techniques that allow them to determine the direct impact of the behavior of knowledgeable individuals on the knowledge or skills of the naive.

Experimental methods. The most direct method for solving the problem of demonstrating an effect of purported teachers on learning by purported pupils is to use experiments. Perhaps the most intuitive technique is to prevent certain naive individuals from being exposed to the behavior of putative teachers and then compare the skills of exposed individuals with those of the controls lacking such exposure. Caro's (1980) experiments on domestic cats did just that, finding that kittens that were exposed to live prey in the presence of their mothers grew into better hunters than did kittens that were exposed only to prey alone. However, such experimental methods are unlikely to be ethical or feasible with wild animals. Moreover, depriving young animals of social interactions may have important deleterious effects that are unrelated to learning (e.g., increased stress levels and deficient neural development; Galvao-Coelho, Silva, Leao, \& de Sousa, 2008). Consequently, the results even of such controlled experiments may not always be clear-cut.

A more effective method may be for researchers to experimentally increase the amount of teaching to which certain naive individuals are exposed, or to begin the exposure of young to teaching earlier in life than would normally occur, and then compare rates of learning in experimental and control individuals. This technique was successfully employed in the studies of both meerkats and pied babblers. The key is to identify the precise aspects of putative teachers' behavior that are hypothesized to promote learning and to replicate them. In meerkats, for example, it was assumed that helpers facilitated the acquisition of handling skills by pups by providing them with otherwise unavailable opportunities to handle live prey. Thornton and McAuliffe (2006) therefore experimentally provisioned pups with four live scorpions a day for 3 days. As was expected, the pups given increased access to live prey subsequently showed greater speed and dexterity in handling live scorpions than did siblings given dead scorpions or an equivalent mass of hardboiled egg. In pied babblers, Raihani and Ridley (2008) used playback experiments to confirm that adults condition chicks to respond to purr calls by reliably pairing these calls with food delivery. Nestlings did not normally respond to purr calls until they were 13 days old. However, if purr calls were played back during feeding visits on Days 9-11, nestlings responded to purr calls by Day 11 . In contrast, playbacks of purr calls outside feeding visits during the same period did not cause nestlings to begin responding early.

Experiments in which researchers act as de facto teachers may be widely applicable. Prey-provisioning experiments such as those conducted on meerkats, for example, may be feasible in a variety of small carnivores and insectivores. Anecdotal reports of teaching exist for several such species (e.g., dwarf mongooses [Helogale parvula; Ewer, 1973] and bat-eared foxes [Otocyon megalotis; Nel, 1999]), and these species are often amenable to habituation, making them particularly promising study systems.

Experiments on raptorial birds or large mammalian carnivores would be considerably more difficult, since releasing live vertebrate prey would not be legally or ethically permissible. Nevertheless, some manipulations may still be possible, particularly in seminatural conditions such as breeding and rehabilitation centers. For example, falconers commonly train raptors to catch their 
quarry, using birdlike lures (Parry-Jones, 1996), and institutions, including the Smithsonian National Zoo in the U.S. (Milius, 2008), the Cheetah Conservation Fund in Namibia (www.cheetah.org), and the Savannah Cheetah Foundation in South Africa (www.scfafrica.co.za), entice cheetahs to chase after high-speed lures, similar to those used in greyhound racing, as part of enrichment schemes. Similar techniques could potentially be used in studies of teaching to replicate the effects of mothers releasing live prey for their young.

Playback experiments, long one of the most useful and widespread experimental tools in studies of wild animal behavior (Cheney \& Seyfarth, 1990, 2007), may also have great potential in the study of teaching. For example, experiments manipulating either the age at which nestlings are first exposed to food calls or the contiguity between calls and food delivery could be invaluable in examining whether other birds, like pied babblers, actively teach their young the meaning of food calls. We speculate that such teaching would be particularly likely in species with a prolonged period of postfledging dependency, where calls could be used to entice offspring to move around the territory or away from danger.

Playbacks may also prove useful in studies of primates. For example, adult golden lion tamarins (Leontopithecus rosalia) preferentially transfer novel foods to the young (Rapaport, 1999). However, in the wild, it is unclear whether this pattern is caused by the novelty of the food per se or by other characteristics, such as nutritional value (Rapaport, 2006). Moreover, although there is some evidence from captive studies that young tamarins are less likely to reject novel items donated by adults than those found independently (Rapaport, 1999), it is not yet known whether social exposure to novel foods promotes their incorporation into the diet. These issues may be elucidated through the use of carefully designed playback experiments. In callitrichid primates, adults use food calls to encourage the young to take proffered food (Rapaport \& Brown, 2008). Experimenters could examine whether playbacks of food calls result in an increase in the probability that the young will sample novel foods and subsequently continue eating these sampled foods whenever they are encountered.

Callitrichid food calls have also been implicated in encouraging the young to forage in specific locations, thereby promoting learning about profitable foraging locations and techniques (Rapaport \& Ruiz-Miranda, 2002). However, as yet, there is little evidence to suggest that calls serve to promote learning, rather than simply increasing the food intake of the young (Thornton et al., 2007). Future studies could address this question by hiding difficult-toobtain rewards in locations indicated by the presence of landmarks. If the young that hear playbacks of food calls at the landmarks are subsequently more likely to approach similar landmarks and successfully obtain food from them than are the young that hear playbacks of control noises, this would provide evidence that adult behavior does promote the acquisition of skills. Such evidence, paired with data showing that adults give food calls only in the presence of food that is either novel or difficult to extract, would substantially support the claim for teaching.
Statistical techniques. Unfortunately, experiments may not always be feasible, particularly in the wild. Nevertheless, the use of powerful statistical tools can substantially strengthen the case for the occurrence of teaching. If learning by the naive is facilitated by the actions of the putative teachers, variation in the behavior of presumed teachers ought to correlate with variation in skill or knowledge acquisition by pupils. For instance, young cheetahs whose mothers bring them live prey at high rates would be expected to learn hunting skills more quickly than cubs that seldom receive live prey. Of course, documentation of all incidences of putative teaching events is unlikely, but sensible sampling may be sufficient to detect consistent differences in the behavior of teachers. Studies of cooperative breeders, for example, have successfully categorized helpers as generous or stingy (Boland, Heinsohn, \& Cockburn, 1997; Clutton-Brock, Russell, Sharpe, \& Jordan, 2005; Hodge, 2005; Hodge, Flower, \& Clutton-Brock, 2007), and recent research on behavioral syndromes suggests that consistent behavioral differences between individuals within populations may be common (Sih, Bell, \& Johnson, 2004).

In species such as cooperative breeders and species with biparental care where more than one individual contributes to teaching, deficiencies in the teaching behavior of one individual may be compensated for by others (Hinde \& Kilner, 2007; Wright \& Dingemanse, 1999). Consequently, correlations between teacher behavior and skill acquisition by pupils may be most likely to be detected in species where only a single teacher is involved. Even in such relatively simple cases, simple correlations may be unlikely to produce convincing evidence for teaching, since multiple factors are likely to contribute to variation in the data. Future studies should therefore use multifactorial models to partition the variance attributed to different sources. These sources could, for example, include measures of food availability and teacher and pupil weight or condition, as well as indices of the amount or quality of teaching. Correlation between variation in teacher behavior and measures of pupil ability, after controlling for other potentially confounding variables, would provide strong evidence for the occurrence of teaching.

\section{CONCLUSION}

Although current evidence for teaching in nonhuman animals is sparse, its rarity is more likely to reflect difficulties in data collection than an absence of teaching per se. In this article, our aim has been to facilitate the identification of teaching by identifying its key characteristics and proposing techniques to accurately detect and measure it. We advocate the use of free-living animals and an experimental approach wherever possible. However, we acknowledge that under many circumstances, this may be unfeasible and suggest methodological and statistical alternatives. Our hope is that, by clarifying concepts and proposing data collection techniques, we will see an increase in documented examples of teaching in nature, improving our understanding of how and why teaching evolved. 


\section{AUTHOR NOTE}

We thank Tim Clutton-Brock and Marta Manser for advice and access to the study site in South Africa. Our work on teaching in meerkats and pied babblers would not have been possible without the collaboration of Katherine McAuliffe and Amanda Ridley. For financial support, we thank Pembroke College, Cambridge (A.T.) and the Zoological Society, London (N.J.R.). Bennett Galef and Rachel Kendal provided useful comments on the manuscript. Correspondence concerning this article should be addressed to A. Thornton, Department of Zoology, University of Cambridge, Downing Street, Cambridge CB2 3EJ, England (e-mail: jant2@cam.ac.uk).

\section{REFERENCES}

Bender, C. E., Herzing, D. L., \& Bjorklund, D. F. (2009). Evidence of teaching in Atlantic spotted dolphins (Stenella frontalis) by mother calves foraging in the presence of their calves. Animal Cognition, 12, 43-53.

Boland, C. R. J., Heinsohn, R., \& Cockburn, A. (1997). Deception by helpers in cooperatively breeding white-winged choughs and its experimental manipulation. Behavioral Ecology \& Sociobiology, 41, 251-256.

Box, H. O., \& Gibson, K. R. (Eds.) (1999). Mammalian social learning: Comparative and ecological perspectives. Cambridge: Cambridge University Press.

Brown, C., \& Laland, K. N. (2003). Social learning in fishes: A review. Fish \& Fisheries, 4, 280-288.

CAfFrey, C. (1992). Female-biased delayed dispersal and helping in American crows. Auk, 109, 609-619.

Canestrari, D., Marcos, J. M., \& Baglione, V. (2007). Costs of chick provisioning in cooperatively breeding crows: An experimental study. Animal Behaviour, 73, 349-357.

CARO, T. M. (1980). Effects of the mother, object play, and adult experience on predation in cats. Behavioral \& Neural Biology, 29, 29-51.

CARo, T. M. (1994). Cheetahs of the Serengeti plains: Grouping in an asocial species. Chicago: University of Chicago Press.

CARo, T. M., \& HAuser, M. D. (1992). Is there teaching in nonhuman animals? Quarterly Review of Biology, 67, 151-174.

Cheney, D. L., \& Seyfarth, R. M. (1990). How monkeys see the world: Inside the mind of another species. Chicago: University of Chicago Press.

Cheney, D. L., \& Seyfarth, R. M. (2007). Baboon metaphysics: The evolution of a social mind. Chicago: University of Chicago Press.

Clarke, J. A. (2010). White-tailed ptarmigan food calls enhance chick diet choice: Learning nutritional wisdom? Animal Behaviour, 79, 25-30

Clemmons, J. R. (1995). Vocalizations and other stimuli that elicit gaping in nestling black-capped chickadees (Parus atricapillus). Auk, 112, 603-612.

Clutton-Brock, T. H. (2007). Meerkat manor: Flower of the Kalahari. London: Weidenfeld \& Nicolson.

Clutton-Brock, T. H., Brotherton, P. N. M., O'Riain, M. J., GrifFin, A. S., Gaynor, D., Kansky, R., ET AL. (2001). Contributions to cooperative rearing in meerkats. Animal Behaviour, 61, 705-710.

Clutton-Brock, T. H., Brotherton, P. N. M., O'Riain, M. J., GrifFin, A. S., GaYnor, D., Sharpe, L., ET AL. (2000). Individual contributions to babysitting in a cooperative mongoose, Suricata suricatta. Proceedings of the Royal Society B, 267, 301-305.

Clutton-Brock, T. H., Russell, A. F., Sharpe, L. L., Brotherton, P. N. M., Mcilrath, G. M., White, S., \& Cameron, E. Z. (2001). Effects of helpers on juvenile development and survival in meerkats. Science, 293, 2446-2449.

Clutton-Brock, T. H., Russell, A. F., Sharpe, L. L., \& Jordan, N. R. (2005). "False-feeding" and aggression in meerkat societies. Animal Behaviour, 69, 1273-1284.

Clutton-Brock, T. H., Russell, A. F., Sharpe, L. L., Young, A. J., Balmforth, Z., \& MCIlrath, G. M. (2002). Evolution and development of sex differences in cooperative behavior in meerkats. Science, 297, 253-256.

Creel, S., \& Creel, N. M. (2002). The African wild dog: Behavior, ecology and conservation. Princeton, NJ: Princeton University Press.
Csibra, G. (2007). Teachers in the wild. Trends in Cognitive Sciences, 11, 95-96.

CURIO, E. (1988). Cultural transmission of enemy recognition by birds. In T. R. Zentall \& B. G. Galef (Eds.), Social learning: Psychological and biological perspectives (pp. 75-97). Hillsdale, NJ: Erlbaum.

Danchin, E., Giraldeau, L. A., Valone, T. J., \& Wagner, R. H. (2004). Public information: From nosy neighbors to cultural evolution. Science, 305, 487-491.

DugatKin, L. A. (1996). Copying and mate choice. In C. M. Heyes \& B. G. Galef, Jr. (Eds.), Social learning in animals: The roots of culture (pp. 85-105). San Diego: Academic Press.

EwER, R. F. (1963). The behaviour of the meerkat, Suricata suricatta (Schreber). Zeitschrift für Tierpsychologie, 20, 570-607.

EwER, R. F. (1969). The "instinct to teach." Nature, 222, 698

EwER, R. F. (1973). The carnivores. Ithaca, NY: Comstock.

Fragaszy, D. M., \& Perry, S. (Eds.) (2003). The biology of traditions: Models and evidence. Cambridge: Cambridge University Press.

FranKs, N. R., \& Richardson, T. (2006). Teaching in tandem-running ants. Nature, $\mathbf{4 3 9}, 153$.

FreeberG, T. M. (2000). Culture and courtship in vertebrates: A review of social learning and transmission of courtship systems and mating patterns. Behavioural Processes, 51, 177-192.

Galef, B. G., JR., \& Giraldeau, L.-A. (2001). Social influences on foraging in vertebrates: Causal mechanisms and adaptive functions. Animal Behaviour, 61, 3-15.

Galef, B. G., Jr., Whiskin, E. E., \& Dewar, G. (2005). A new way to study teaching in animals: Despite demonstrable benefits, rat dams do not teach their young what to eat. Animal Behaviour, 70, 91-96.

Galvao-Coelho, N. L., Silva, H. P. A., Leao, A. D., \& De Sousa, M. B. C. (2008). Common marmosets (Callithrix jacchus) as a potential animal model for studying psychological disorders associated with high and low responsiveness of the hypothalamic-pituitaryadrenal axis. Reviews in the Neurosciences, 19, 187-201.

GASTON, A. J. (1978). Evolution of group territorial behavior and cooperative breeding. American Naturalist, 112, 1091-1100.

GRIFFIN, A. S. (2004). Social learning about predators: A review and prospectus. Learning \& Behavior, 32, 131-140.

GuINET, C., \& Bouvier, J. (1995). Development of intentional stranding hunting techniques in killer whale (Orcinus orca) calves at Crozet Archipelago. Canadian Journal of Zoology, 73, 27-33.

HAMILTON, W. D. (1964). The genetical evolution of social behaviour. Journal of Theoretical Biology, 7, 1-52.

Heinsohn, R., \& LegGe, S. (1999). The cost of helping. Trends in Ecology \& Evolution, 14, 53-57.

Hinde, C. A., \& KILnER, R. M. (2007). Negotiations within the family over the supply of parental care. Proceedings of the Royal Society $B$, 274, 53-60.

Hodge, S. J. (2005). Helpers benefit offspring in both the short and long-term in the cooperatively breeding banded mongoose. Proceedings of the Royal Society B, 272, 2479-2484.

Hodge, S. J., Flower, T. P., \& Clutton-Brock, T. H. (2007). Offspring competition and helper associations in a cooperative breeder. Animal Behaviour, 74, 957-964.

Hoelzel, A. R. (1991). Killer whale predation on marine mammals at Punta Norte, Argentina; food sharing, provisioning and foraging strategy. Behavioral Ecology \& Sociobiology, 29, 197-204.

Hofer, H., \& EAST, M. L. (2008). Siblicide in Serengeti spotted hyenas: A long-term study of maternal input and cub survival. Behavioral Ecology \& Sociobiology, 62, 341-351.

Hoppitt, W. J. E., Brown, G. R., Kendal, R., Rendell, L., Thornton, A., Webster, M. M., \& Laland, K. N. (2008). Lessons from animal teaching. Trends in Ecology \& Evolution, 23, 486-493.

JANIK, V. M., \& SLATER, P. J. B. (2000). The different roles of social learning in vocal communication. Animal Behaviour, 60, 1-11.

Kokko, H., Johnstone, R. A., \& Clutton-Brock, T. H. (2001). The evolution of cooperative breeding through group augmentation. Proceedings of the Royal Society B, 268, 187-196.

LALAND, K. N., \& HoppITT, W. (2003). Do animals have culture? Evolutionary Anthropology, 12, 150-159.

Leadbeater, E., \& ChitTKa, L. (2007). Social learning in insects: From miniature brains to consensus building. Current Biology, 17, R703-R713. 
Leadbeater, E., Raine, N. E., \& ChittKa, L. (2006). Social learning: Ants and the meaning of teaching. Current Biology, 16, R323-R325.

LeEming, J. (2003). Scorpions of southern Africa. Cape Town: Struik.

Lefebvre, L. (2000). Feeding innovations and their cultural transmission in bird populations. In C. M. Heyes \& L. Huber (Eds.), The evolution of cognition (pp. 311-328). Cambridge, MA: MIT Press.

Leonard, M. L., Fernandez, N., \& Brown, G. (1997). Parental calls and nestling behavior in tree swallows. Auk, 114, 668-672.

Lessells, C. M., Rowe, C. L., \& McGregor, P. K. (1995). Individual and sex differences in the provisioning calls of European bee-eaters. Animal Behaviour, 49, 244-247.

LONSDORF, E. V. (2006). What is the role of mothers in the acquisition of termite-fishing behaviors in wild chimpanzees (Pan troglodytes schweinfurthii)? Animal Cognition, 9, 36-46.

Madden, J. R., Kilner, R. M., \& Davies, N. B. (2005). Nestling responses to adult food and alarm calls: 1 . Species-specific responses in two cowbird hosts. Animal Behaviour, 70, 619-627.

Maestripieri, D. (1995). First steps in the macaque world: Do rhesus mothers encourage their infants' independent locomotion? Animal Behaviour, 49, 1541-1549.

MaestriPIERI, D. (1996). Maternal encouragement of infant locomotion in pigtail macaques, Macaca nemestrina. Animal Behaviour, 51, 603-610.

Matsuzawa, T., Biro, D., Humle, T., Inoue-NaKamura, N., ToNOOKA, R., \& YAMAKOSHI, G. (2001). Emergence of culture in wild chimpanzees: Education by master-apprenticeship. In T. Matsuzawa (Ed.), Primate origins of human cognition and behavior (pp. 557574). Berlin: Springer.

Maurer, G., Magrath, R. D., Leonard, M. L., Horn, A. G., \& DonNELLY, C. (2003). Begging to differ: Scrubwren nestlings beg to alarm calls and vocalize when parents are absent. Animal Behaviour, 65, 1045-1055.

Midford, P. E., Hailman, J. P., \& Woolfenden, G. E. (2000). Social learning of a novel foraging patch in families of free-living Florida scrub-jays. Animal Behaviour, 59, 1199-1207.

Milius, S. (2008). Built for speed. Science News, 174, 1.

NeL, J. A. J. (1999). Social learning in canids: An ecological perspective. In H. O. Box \& K. R. Gibson (Eds.), Mammalian social learning: Comparative and ecological perspectives (pp. 259-278). Cambridge: Cambridge University Press.

Nicol, C. J., \& PoPE, S. J. (1996). The maternal feeding display of domestic hens is sensitive to perceived chick error. Animal Behaviour, 52, 767-774.

Parry-Jones, J. (1996). Training birds of prey. Newton Abbot, U.K.: David \& Charles.

Premack, D. (2007). Human and animal cognition: Continuity and discontinuity. Proceedings of the National Academy of Sciences, 104, 13861-13867.

Premack, D., \& Premack, A. J. (1996). Why animals lack pedagogy and some cultures have more of it than others. In D. R. Olson \& N. Torrance (Eds.), The handbook of education and human development: New models of learning, teaching, and schooling (pp. 302-323). Cambridge, MA: Blackwell.

RADFORD, A. N., \& RIDLEY, A. R. (2006). Recruitment calling: A novel form of extended parental care in an altricial species. Current Biology, 16, 1700-1704

RAIHANI, N. J. (2008). Cooperation and conflict in pied babblers. Unpublished doctoral thesis, University of Cambridge.

RAIHANI, N. J., \& RIDLEY, A. R. (2007). Adult vocalizations during provisioning: Offspring responses and postfledging benefits in wild pied babblers. Animal Behaviour, 74, 1303-1309.

Raihani, N. J., \& Ridley, A. R. (2008). Experimental evidence for teaching in wild pied babblers. Animal Behaviour, 75, 3-11.

RAPAPORT, L. G. (1999). Provisioning of young in golden lion tamarins (Callitrichidae, Leontopithecus rosalia): A test of the information hypothesis. Ethology, 105, 619-636.

RAPAPORT, L. G. (2006). Provisioning in wild golden lion tamarins (Leontopithecus rosalia): Benefits to omnivorous young. Behavioral Ecology, 17, 212-221

RAPAPORT, L. G., \& BROWN, G. R. (2008). Social influences on foraging behavior in young nonhuman primates: Learning what, where, and how to eat. Evolutionary Anthropology, 17, 189-201.
RAPAPORT, L. G., \& Ruiz-Miranda, C. R. (2002). Tutoring in wild golden lion tamarins. International Journal of Primatology, 23, 10631070.

Richardson, T. O., Houston, A. I., \& Franks, N. R. (2007). Teaching with evaluation in ants. Current Biology, 17, 1520-1526.

Richerson, P. J., \& Boyd, R. (2005). Not by genes alone: How culture transformed human evolution. Chicago: University of Chicago Press.

RidLEY, A. R., \& RAIHANI, N. J. (2007). Variable postfledging care in a cooperative bird: Causes and consequences. Behavioral Ecology, 18, $994-1000$

SCHENKel, R. (1966). Play, exploration, and territory in the wild lion. Symposium of the Zoological Society of London, 18, 11-22.

Sin, A., Bell, A., \& Johnson, J. C. (2004). Behavioral syndromes: An ecological and evolutionary overview. Trends in Ecology \& Evolution, 19, 372-378.

Stander, P. E. (1992). Cooperative hunting in lions: The role of the individual. Behavioral Ecology \& Sociobiology, 29, 445-454.

Strauss, S., Ziv, M., \& Stein, A. (2002). Teaching as a natural cognition and its relations to preschoolers' developing theory of mind. Cognitive Development, 17, 1473-1487.

Thornton, A. (2008a). Social learning about novel foods by young meerkats. Animal Behaviour, 76, 1411-1421.

THORNTON, A. (2008b). Variation in contributions to teaching by meerkats. Proceedings of the Royal Society B, 275, 1745-1751.

Thornton, A., \& Malapert, A. (2009). Experimental evidence for social transmission of food acquisition techniques in wild meerkats. Animal Behaviour, 78, 255-264.

Thornton, A., \& McAulifFe, K. (2006). Teaching in wild meerkats. Science, 313, 227-229.

Thornton, A., \& RaIHANi, N. J. (2008). The evolution of teaching. Animal Behaviour, 75, 1823-1836.

Thornton, A., RaiHANi, N. J., \& RADFord, A. N. (2007). Teachers in the wild: Some clarification. Trends in Cognitive Sciences, 11, 272-273.

Tomasello, M., Kruger, A. C., \& Ratner, H. H. (1993). Cultural learning. Behavioral \& Brain Sciences, 16, 495-552.

West, S. A., Griffin, A. S., \& Gardner, A. (2007). Social semantics: Altruism, cooperation, mutualism, strong reciprocity and group selection. Journal of Evolutionary Biology, 20, 415-432.

Whiten, A., \& Mesoudi, A. (2008). Establishing an experimental science of culture: Animal social diffusion experiments. Philosophical Transactions of the Royal Society B, 363, 3477-3488.

Whiten, A., \& VAN SchaIK, C. P. (2007). The evolution of animal "cultures" and social intelligence. Philosophical Transactions of the Royal Society B, 362, 603-620

Williamson, E. A., \& Feistner, A. T. C. (2003). Habituating primates: Processes, techniques, variables and ethics. In J. M. Setchell \& D. J. Curtis (Eds.), Field and laboratory methods in primatology: A practical guide (pp. 25-39). Cambridge: Cambridge University Press.

Woolfenden, G. E., \& FitzPatrick, J. W. (1984). The Florida scrub jay: Demography of a cooperative breeding bird. Princeton, NJ: Princeton University Press.

Wright, J. (1997). Helping-at-the-nest in Arabian babblers: Signalling social status or sensible investment in chicks? Animal Behaviour, $\mathbf{5 4}$ 1439-1448.

Wright, J., \& Dingemanse, N. J. (1999). Parents and helpers compensate for experimental changes in the provisioning effort of others in the Arabian babbler. Animal Behaviour, 58, 345-350.

Wright, J., Hinde, C., FAZEY, I., \& Both, C. (2002). Begging signals more than just short-term need: Cryptic effects of brood size in the pied flycatcher (Ficedula hypoleuca). Behavioral Ecology \& Sociobiology, 52, 74-83.

Zahavi, A. (1995). Altruism as a handicap: The limitations of kin selection and reciprocity. Journal of Avian Biology, 26, 1-3.

\section{SUPPLEMENTAL MATERIALS}

Additional mixed model results for this article, as well as a list of species habituated to close observation in the wild and the studies in which they appear, may be downloaded from http://lb.psychonomic-journals org/content/supplemental.

(Manuscript received February 2, 2010; revision accepted for publication April 22, 2010.) 